\title{
Statement on Virginity Testing
}

\author{
Independent Forensic Expert Group*
}

\section{Introduction}

Virginity testing (also referred to as virginity examination) is a gynaecological examination that is intended to correlate the status and appearance of the hymen in females with previous sexual contact to determine whether a female has had or is habituated to sexual intercourse. The exam is conducted by visual inspection of the hymenal region, and is often combined with a 'two-finger test', which involves the insertion of one or more fingers into the vagina to assess the size of the vaginal opening and to check the degree of vaginal penetrability.

Virginity examinations are practiced in many countries, and often forcibly, in a number of contexts, including in detention places; on women who allege rape; on women who are accused by authorities of prostitution; and as part of public or social policies to control sexuality. In other states, the practice is illegal.

The purpose of this medico-legal statement is to provide legal experts,

\footnotetext{
*) Djordje Alempijevic, Rusudan Beriashvili, Jonathan Beynon, Ana Deutsch, Maximo Duque, Pierre Duterte, Adriaan van Es, Ravindra Fernando, Sebnem Korur Fincanci, Steen Holger Hansen, Lilla Hardi, Hans Petter Hougen, Vincent Iacopino, Peter Mygind Leth, Said Louahlia, Maria Cristina Mendonça, Jens Modvig, Maria-Dolores Morcillo Mendez, Önder Özkalipci, Jason Payne-James, Jose Quiroga, Ole Vedel Rasmussen, Hernán Reyes, Sidsel Rogde, Antti Sajantila, Daya Somasundaram, Jørgen Lange Thomsen, Morris TidballBinz, Felicitas Treue, Peter Vanezis, Duarte Nuno Viera

Correspondence to irct@irct.org
}

For full details about the Independent Forensic Expert Group please visit http://www.irct.org/our-support/ medical-and-psychological-case-support/forensic-expertgroup.aspx. adjudicators, healthcare professionals and policy makers, among others, with an understanding of the physical and psychological effects of forcibly conducting virginity examinations on females ${ }^{\mathrm{ii}}$ and to assess whether, based on these effects, forcibly conducted virginity examinations constitute cruel, inhuman, or degrading treatment or torture. This medico-legal statement also addresses the medical interpretation and relevance of such examinations and the ethical implications. This opinion considers an examination to be 'forcibly conducted' when it is "committed by force, or by threat of force or coercion, such as caused by fear of violence, duress, detention, psychological oppression or abuse of power, against such person incapable of giving genuine consent." ${ }_{\text {iii, } 1}$

While this opinion concerns itself with the medico-legal implications of forcibly conducted virginity examinations, many of the facts and issues addressed herein are generally applicable to all virginity examinations.

The opinions expressed in this statement are based on international standards and the experiences of members of the Independent Forensic Expert Group (IFEG) in documenting the physical and psychological effects of torture and ill-treatment. Consist-

\footnotetext{
${ }^{\mathrm{i}}$ Virginity examinations do not include similar examinations conducted for other purposes such as body cavity searches, although the facts and issues addressed in this statement may be applicable to the latter.

ii This statement focuses on virginity examinations forcibly conducted on postpubescent females (women). It does not address the particular and specialised concerns relating to prepubescent females.

iii The International Criminal Court has adopted this standard on lack of consent in the crimes of rape.
} 
ing of thirty-five preeminent independent forensic specialists from eighteen countries, the IFEG represents a vast collective experience in the evaluation and documentation of the physical and psychological evidence of torture and ill-treatment.

The IFEG provides technical advice and expertise in cases where allegations of torture and/or ill-treatment are made. ${ }^{\text {iv }}$ Its members are global experts on and include several authors of the Istanbul Protocol, the key international standard-setting instrument on the investigation and documentation of torture and ill-treatment. ${ }^{2}$

IFEG members also hold influential positions in and act as advisors to governments, international bodies, professional health associations, non-governmental organisations, and academic institutions worldwide on forensics in general and more specifically on the investigation and documentation of torture.

\section{Background}

Virginity examinations are premised on a correlation between the practice of sexual intercourse and immorality or criminal deviancy. By nature, as they can only be conducted on females and are generally only conducted on those who are unmarried, the examinations are discriminatory.

In the justice context, correlating virginity to purity elevates the repugnance of sexual violence against women who are 'virgins'. Yet, it similarly diminishes the perception of the severity of sexual violence

\footnotetext{
iv See e.g., Independent Forensic Expert Group. Statement on Hooding. Torture. 2011; 21(3):186-189; Independent Forensic Expert Group. Statement on access to relevant medical and other health records and relevant legal records for forensic medical evaluations of alleged torture and other cruel, inhuman or degrading treatment or punishment. Torture. 2012; 22 (Supplementum 1):39-48.
}

against women who have previously engaged in sexual intercourse; and it has been used to suggest that those women are somehow responsible for the acts perpetrated against them.

Virginity examinations are often conducted forcibly - without the consent of the women or in circumstances where women are not capable of giving genuine consent. This may be presumed to be the case when examinations are conducted on women in detention, sometimes subsequent to allegations of rape by victims or of prostitution by the authorities.

A plethora of jurisprudence has found the practice of virginity examination to violate international human rights standards. In many countries, virginity examinations are explicitly prohibited or criminalised under the overarching national laws against sexual assault and rape. According to the United Nations (UN) Rules for the Treatment of Women Prisoners and Non-custodial Measures for Women Offenders (the "Bangkok Rules"), women have the right not to undergo screening in relation to their reproductive health history. ${ }^{3}$

The World Health Organization, ${ }^{4}$ the UN Special Rapporteur on Torture and Cruel, Inhuman or Degrading Treatment or Punishment, ${ }^{5}$ and the UN Special Rapporteur on Violence Against Women, Its Causes and Consequences ${ }^{6}$ all consider virginity examination to be a form of sexual violence. ${ }^{v}$

In 2005, the UN Committee on the Elimination of Discrimination against

\footnotetext{
v According to the World Health Organization, other forms of sexual violence include, but are not limited to: sexual slavery; sexual harassment (including demands for sex in exchange for job promotion or advancement or higher school marks or grades); trafficking for purposes of forced prostitution; forced exposure to pornography; forced pregnancy; forced sterilisation; forced abortion; forced marriage; and female genital mutilation.
} 
Women expressed concern that certain provisions of the Civil and Penal Codes of the Republic of Turkey permitted virginity examinations to be conducted on women without their consent. ${ }^{7}$ In 2010 , the UN Committee against Torture expressed concern that judges and prosecutors in Turkey could order a virginity examination in rape cases against the will of women. ${ }^{8}$

The European Court of Human Rights in 2009 held that two women in police detention were subjected to severe ill-treatment when they were forced to submit to virginity examinations without their consent, purportedly subsequent to allegations of sexual violence. ${ }^{9}$ As a result of the forcibly conducted virginity examinations, both women suffered from post-traumatic stress disorder, and one of them suffered from serious depressive disorder. ${ }^{\mathrm{vi}}$

\section{Physical and Psychological Effects}

\section{A. General Effects}

A number of physical and psychological effects result from the act of conducting virginity examinations forcibly on women.

These examinations can cause physical pain, and can lead to damage to the hymen, bleeding, and to infection. Psychologically, the pain and suffering caused by these examinations is especially acute.

Forcibly conducting virginity examinations on women violates the autonomy of women in relation to their own body and sexual decision-making. In so doing, these examinations cause significant mental pain

\footnotetext{
${ }^{v i}$ Also, the Inter-American Court of Human Rights has ruled that "the acts of sexual violence to which an inmate was submitted under an alleged finger vaginal 'examination' constituted sexual rape that due to its effects constituted torture.” Inter-Am. Ct. H.R. Miguel Castro-Castro Prison v. Peru. Judgment of 25 Nov. 2006. 2006 Inter-Am. Ct. H.R. (ser. C) No. 160. para. 312 .
}

and suffering in almost all instances. When undertaken in a detention setting, they can be particularly traumatic because of the ease in which the state exploits these women's vulnerability and weakened resistance. ${ }^{10}$

The pain and suffering caused by forcibly conducting virginity examinations may manifest as severe emotional pain, as well as fear, a sense of powerlessness or denial. Irrespective of the findings of these examinations, conducting them forcibly also leads women to feel intense humiliation, self-disgust, and worthlessness. Women are often stricken by apathy, emotional numbing, and withdrawal, which contribute to difficulties in functioning normally in daily life.

Due to their sexual and invasive nature, forcibly conducted virginity examinations are likely to cause severe and lasting psychological symptoms and disabilities that do not respond to the passage of time as quickly as other forms of physical and mental violence.

Long-term psychological conditions include anxiety, depression, and the symptoms of post-traumatic stress disorderamong them, recurrent and distressing memories or nightmares; severe emotional distress and physical reactions; negative changes in thinking and mood; feelings of hopelessness; irritability, angry outbursts, and aggressive behaviour; and overwhelming guilt and shame.

Women who are subjected forcibly to virginity examinations may also exhibit serious psychosomatic symptoms (psychological distress that manifests as physical symptoms) as well as self-destructive and self-harming behaviour.

Conducting virginity examinations forcibly on women often stigmatises these women because it violates their personal integrity. Together, the traumatic effects of these examinations corrode the women's ability to maintain familial and social 
relationships and may lead to the collapse of those relationships.

The findings of the virginity examination, whether accurate or not, may also have adverse legal and social consequences, including the loss of access to schooling or other social benefits, exclusion from marriage, and an inability to access the justice system or to obtain appropriate redress for wrongful acts committed against these women.

Ultimately, in some cases, women have committed suicide incident to these examinations or the effects and consequences thereof. ${ }^{\text {vii }}$ In other instances, women have been assaulted and murdered when examinations have indicated that those women were not virgins.

\section{B. "Two-Finger Test"}

When a forcibly conducted virginity examination involves the physical invasion of the woman's body, such as when the 'two-finger test' is applied, trauma may be especially pronounced. Penetration of these women's bodies against their consent violates their integrity, their privacy, and further disempowers them, thereby leading to heightened or particularised traumas.

When the examination is applied incident to an allegation of sexual violence, the procedure may mimic the alleged violence and constitute a second and repetitive traumatic event for the victim. The examination is also inherently coercive because refusal to submit to the examination following an allegation of sexual violence will be interpreted as a sign of duplicity.

Because of the severe pain and suffering that is especially likely to occur as a result of

\footnotetext{
vii Testimonies provided to members of the Independent Forensic Expert Group.
}

the forcibly undertaken sexual invasion of an individual's physical body, international legal jurisprudence defines such an invasion "of the body of a person by conduct resulting in penetration, however slight, of any part of the body of the victim or the perpetrator with a sexual organ or of the anal or genital opening of the victim with any object or any other part of the body" as rape. ${ }^{1, \text { vii }}$

\section{Additional Factors}

In many circumstances when virginity examinations are forcibly conducted, they are accompanied by other forms of abuse. For instance, examinations are likely to involve unconsented touching or groping, which is always traumatic. ${ }^{2}$ In addition, threats, coercion, or physical force are often applied.

In detention settings, virginity examinations have been conducted forcibly in the view of others, including male guards, and incident to verbal and sexual threats and mocking. These abuses enhance the sense of helplessness, fear, humiliation, degradation, and stigma experienced by these women and their subsequent pain and suffering.

Forced nudity is also a frequent part of the experience and magnifies the psychological terror of every aspect of ill-treatment, including the examination itself and any threats and humiliation. ${ }^{2}$

\footnotetext{
viii "It is noteworthy that other forms of sexual violence, whether defined as rape or not, may constitute torture or ill-treatment and must not be dealt with as minor offences." United Nations. Promotion and protection of all human rights, civil, political, economic, social and cultural rights, including the right to development: report of the Special Rapporteur on Torture and Other Cruel, Inhuman or Degrading Treatment or Punishment, Manfred Nowak. United Nations; 2008 Jan. A/HRC/7/3. para 35.
} 


\section{Medical Perspectives}

\section{A. Reliability}

Published and peer-reviewed medical literature establishes that virginity examinations have no scientific value. ${ }^{11,12,13}$ The status of the hymen has no correlation with previous penetration or sexual contact; it does not enable a determination of whether penetration of the hymen or vagina by a penis or any other object has occurred. Virginity examinations also do not assist in the detection of sexually transmitted infections.

While examination of the hymen may, in very limited contexts, be useful in the diagnosis of sexual assault in prepubescent females, it is not an indicator of sexual intercourse or habituation. An individual with an undamaged hymen may or may not have experienced penetrative sexual contact. There similarly may be no trace of hymenal lesion following sexual assault.

At puberty, the hymen is exposed to oestrogen, which alters its appearance, shape, and elasticity. Studies demonstrate that hymen configurations vary, and the hymen may exhibit changes prior to sexual intercourse. ${ }^{11,12,13}$ The belief that absence of the hymen confirms that there has been penetration of the vagina is incorrect; equally false is the notion that the presence of a 'normal' or 'intact' hymen means that penetration has not occurred.

Further illustrating the non-utility of this type of examination, in a survey of forensic physicians conducted in Turkey, two-thirds of respondents reported that their findings from at least one virginity examination conducted in the previous twelve months contradicted a recent virginity examination of the same patient. In 73 percent of those cases, the contradictory findings were made by general practitioners or gynaecologists. ${ }^{12}$

\section{B. Virginity}

Virginity examinations are not only meaningless in determining whether a female is a virgin, they are also medically irrelevant. There is no medically significant value that can be attributed to virginity. Ascribed values to virginity are wholly moral, social, and cultural.

The concept of virginity also has no relevance to the forensic medical examination, diagnosis, and documentation of sexual assault. The knowledge of a woman's sexual background adds no information to the medical determination of whether that woman has been sexually assaulted. Nor does the fact of virginity necessarily make an individual's pain and suffering from sexual assault more or less severe.

Health professionals therefore have no medical foundation for conducting virginity examinations; the examinations are irrelevant and harmful to women, and serve as a form of social control of their sexuality.

\section{Professional and Ethical Standards}

International standards of professional ethics prohibit health professionals from participating in or condoning any treatment or procedure that may amount to cruel, inhuman, or degrading treatment or torture. ${ }^{14,15}$

There is no medical or healthcare foundation for conducting virginity examinations. When forcibly conducted, these examinations are likely, in almost all instances, to cause women significant pain and suffering. These examinations therefore constitute cruel, inhuman, and degrading treatment and may amount to torture depending on the individual circumstances.

The potential for pain and suffering caused by conducting virginity examinations forcibly on women will not necessarily diminish because a health professional is the 
one undertaking the procedure and may qualify it as 'diagnostic' or medical' in nature. In some instances, the fact that a health professional - who has an ethical duty of care to individuals - is the one that is violating their trust may contribute to these women's subsequent trauma, and should render that health professional subject to censure by their professional body.

Health professional ethics also dictate that health professionals must respect the rights and preferences of the individual, and any interactions, whatever their nature, must be solely for the best interests of those individuals. In addition, the purpose of any intervention must be clearly explained to individuals, and individuals must give voluntary and informed consent for the undertaking of any intervention. ${ }^{17}$

Following from these core ethical standards, health professionals should never forcibly conduct virginity examinations - i.e., against the will or without the consent of women or in circumstances where women are not capable of giving genuine informed consent.

Professional health ethics permit the carrying out of diagnostic procedures and treatment against an individual's will only in exceptional circumstances, if specifically permitted by law, and even then, if and only if conforming to the basic principles of medical ethics. ${ }^{17}$ In general, an individual has the right to give or withhold consent to any diagnostic procedure or therapy. ${ }^{17} \mathrm{An}$ individual's right to self-determination may be breached only if there is a real and imminent threat of harm to the patient or others and this threat cannot be remedied otherwise. ${ }^{\text {ix }}$

\footnotetext{
ix Communications with the World Medical Association,
} May 2014 .
It is difficult to imagine a situation in which virginity examinations could meet this standard since they are erroneous and provide no interpretable information. In addition, the examinations are medically unjustified and are likely to cause women significant pain and suffering when they are conducted forcibly.

Health professionals that conduct these examinations forcibly upon women violate the basic standards and ethics of the profession and should be reported by their colleagues to the appropriate authorities. ${ }^{16}$

\section{Conclusion}

Virginity examinations are medically unreliable and inherently discriminatory, and, in almost all instances, when conducted forcibly, result in significant physical and mental pain and suffering. It is our opinion that forcibly conducted virginity examinations have no clinical or scientific value and constitute cruel, inhuman and degrading treatment, and may amount to torture depending on the individual circumstances.

When virginity examinations are forcibly conducted and involve vaginal penetration, the examination should be considered a form of sexual assault and rape. The involvement of the health professional in these examinations is a violation of the basic standards and ethics of our profession. 


\section{References}

1. International Criminal Court. Elements of Crimes, 2011; RC/11. Arts. 7(1)(g)-1, 8(2)(b) (xxii)-1, \& 8(2)(e)(vi)-1, pp. 8, 28, 36.

2. United Nations Office of the High Commissioner for Human Rights. Manual on the Effective Investigation and Documentation of Torture and Other Cruel, Inhuman or Degrading Treatment or Punishment (the "Istanbul Protocol"). United Nations; 2004. HR/P/PT/8/Rev.1.

3. United Nations. Rules for the Treatment of Women Prisoners and Non-custodial Measures for Women Offenders (the "Bangkok Rules"). United Nations; 2010 Oct. A/C.3/65/L.5.

4. World Health Organization. Guidelines for the Medico-legal Care for Victims of Sexual Violence. World Health Organization; 2003 Jan.

5. United Nations. Promotion and protection of all human rights, civil, political, economic, social and cultural rights, including the right to development: report of the Special Rapporteur on Torture and Other Cruel, Inhuman or Degrading Treatment or Punishment, Manfred Nowak. United Nations; 2008 Jan. A/HRC/7/3.

6. United Nations. Preliminary report submitted by the Special Rapporteur on Violence Against Women, Its Causes and Consequences, Rashika Coomaraswamy, in accordance with Commission on Human Rights resolution 1994/45. United Nations; 1994 Nov. E/CN.4/1995/42.

7. United Nations. Report of the Committee on the Elimination of Discrimination against Women. United Nations; 2005 July. CEDAW/A/60/38.

8. United Nations Committee against Torture. Concluding Observations on Turkey. United Nations; 2011. CAT/C/TUR/CO/3.
9. Eur. Ct. H.R. Salmanoglu and Polattas v. Turkey. Judgment 15828/03. 17 Jun. 2009.

10. Eur. Ct. H.R. Aydin v. Turkey. , Judgment 57/1996/676/866. 25 Sept. 1997.

11. Frank M, Bauer H, Arican N, Fincanci S, Iacopino V. Virginity examinations in Turkey: Role of forensic physicians in controlling female sexuality. JAMA 1999, Aug; Vol. 282(5); 485-90.

12. Anderst J, Kellogg N, Jung I. Reports of repetitive penile-genital penetration often have no definitive evidence of penetration. Pediatrics 2009, Sep;124(3):e403-9. doi: 10.1542/peds.20083053. Epub 2009 Aug 3.

13. McCann J, Miyamoto S, Boyle C, Rogers K. Healing of hymenal injuries in prepubertal and adolescent girls: a descriptive study. Pediatrics 2007, May;119(5):e1094-106. Epub 2007 Apr 9.

14. World Medical Association. WMA Declaration of Tokyo - Guidelines for Physicians Concerning Torture and other Cruel, Inhuman or Degrading Treatment or Punishment in Relation to Detention and Imprisonment. World Medical Assembly; 1975. Rev. 2006.

15. United Nations. Body of principles for the protection of all persons under any form of detention or imprisonment. United Nations; 1988 Dec $\mathrm{A} / \mathrm{RES} / 43 / 173$.

16. World Medical Association. International Code of Medical Ethics. World Medical Assembly; 1949. Rev. 2006.

17. World Medical Association. Declaration of Lisbon on the Rights of the Patient. World Medical Assembly; 1981. Rev. 2005. 